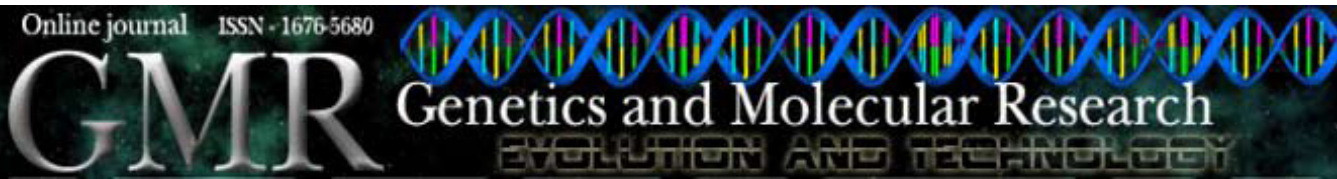

\title{
Molecular cloning and expression of epsilon toxin from Clostridium perfringens type $D$ and tests of animal immunization
}

\author{
A.M. Souza ${ }^{1,2}$, J.K.P. Reis ${ }^{3}$, R.A. Assis ${ }^{4}$, C.C. Horta ${ }^{1}$, F.F. Siqueira ${ }^{1}$, \\ S. Facchin ${ }^{1}$, E.R. Alvarenga ${ }^{1}$, C.S. Castro ${ }^{1}$, F.M. Salvarani ${ }^{2}$, R.O.S. Silva ${ }^{2}$, \\ P.S. Pires ${ }^{2}$, C. Contigli ${ }^{5}$, F.C.F. Lobato ${ }^{2 *}$ and E. Kalapothakis ${ }^{1 *}$ \\ ${ }^{1}$ Laboratório de Marcadores Moleculares e Biotecnologia, \\ Universidade Federal de Minas Gerais, Belo Horizonte, MG, Brasil \\ ${ }^{2}$ Laboratório de Anaeróbios, Escola de Veterinária, \\ Universidade Federal de Minas Gerais, Belo Horizonte, MG, Brasil \\ ${ }^{3}$ Laboratório de Retroviroses da Escola de Veterinária, Belo Horizonte, MG, Brasil \\ ${ }^{4}$ Laboratório Nacional Agropecuário/Pedro Leopoldo/Minas Gerais, \\ Ministério da Agricultura, Belo Horizonte, MG, Brasil \\ ${ }^{5}$ Fundação Centro Tecnológico de Minas Gerais (CETEC), \\ Belo Horizonte, MG, Brasil \\ *These authors contributed equally to this study. \\ Corresponding author: E. Kalapothakis \\ E-mail: ekalapo@icb.ufmg.br
}

Genet. Mol. Res. 9 (1): 266-276 (2010)

Received October 13, 2009

Accepted November 9, 2009

Published February 18, 2010

\begin{abstract}
Epsilon toxin produced by Clostridium perfringens types $\mathrm{B}$ and D causes enterotoxemia in sheep, goats and calves. Enterotoxemia can cause acute or superacute disease, with sudden death of the affected animal. It provokes huge economic losses when large numbers of livestock are affected. Therapeutic intervention is challenging, because the disease progresses very rapidly. However, it can be prevented by immunization with specific immunogenic vaccines. We cloned the etx gene, encoding epsilon toxin, into vector pET-11a; recombinant epsilon toxin (rec- $\varepsilon$ ) was expressed in inclusion bodies and was used for animal immunization. Serum protection was evaluated and cross-serum neutralization tests were used to characterize the recombinant toxin. To analyze the potency of the
\end{abstract}


toxin (as an antigen), rabbits were immunized with 50,100 or $200 \mu \mathrm{g}$ recombinant toxin, using aluminum hydroxide gel as an adjuvant. Titers of 10,30 and $40 \mathrm{IU} / \mathrm{mL}$ were obtained, respectively. These titers were higher than the minimum level required by the European Pharmacopoeia $(5 \mathrm{IU} / \mathrm{mL})$ and by the USA Code of Federal Regulation $(2 \mathrm{IU} / \mathrm{mL})$. This rec- $\varepsilon$ is a good candidate for vaccine production against enterotoxemia caused by epsilon toxin of $C$. perfringens type $\mathrm{D}$.

Key words: Clostridium perfringens; Epsilon toxin; etx gene; Vaccine; Enterotoxemia

\section{INTRODUCTION}

Clostridium perfringens is an anaerobic, Gram-positive, rod-shaped, spore-forming bacterium. It is ubiquitous in the environment, being found in soil, water and decaying organic matter, and it is part of the normal intestinal flora of humans and animals (Titball et al., 1999; McClane, 2005). It is responsible for a wide range of diseases, including food poisoning, lamb dysentery, enterotoxemia, gas gangrene, hemorrhagic enteritis in humans and many severe enterotoxemic diseases in domestic animals (Niilo, 1980; Sterne, 1981; Rood, 1998). Clostridium perfringens can be classified into five toxinotypes (A to E) based on the production of four major toxins (alpha, beta, epsilon, and iota). However, this bacterium also produces 10 other toxins, including C. perfringens enterotoxin, beta2 toxin, and theta toxin (also known as perfringolysin O) (McDonel, 1986; Petit et al., 1999; McClane, 2005).

Epsilon toxin, a major lethal toxin, is produced by C. perfringens types $\mathrm{B}$ and $\mathrm{D}$ and is responsible for a rapidly fatal enterotoxemia in economically important livestock (McDonel, 1986; Finnie, 2004). Enterotoxemia resulting from infection with $C$. perfringens type B is initiated by the proliferation of these bacteria in the gut. Toxins are then produced, which initially act on the intestines, but are later absorbed through the intestinal mucosa and then affect internal organs. A similar enterotoxemia is caused by type D isolates in sheep and goats, in which circulating toxins lead to elevated blood pressure, fluid accumulation in body cavities, and edema in the brain, heart, lungs, liver, and kidneys (Miyamoto et al., 2008). Disease occurs when the microbial balance in the gut is disrupted, often as a consequence of changes in diet, resulting in large amounts of this toxin being produced (Soler-Jover et al., 2007).

We produced a recombinant form of epsilon toxin (rec- $\varepsilon$ ) from C. perfringens type $\mathrm{D}$ in Escherichia coli. Rec- $\varepsilon$ was subjected to biochemical and pharmacological characterization and then used for the production of neutralizing antibodies.

\section{MATERIAL AND METHODS}

\section{Bacterial strains}

U10, a C. perfringens type D strain from the Anaerobium Laboratory of the Veterinary School at the Federal University of Minas Gerais (UFMG, Belo Horizonte, Brazil), was used. This strain is a clone that was selected by a dot-blot test designed to identify clones producing high levels of epsilon toxin (Aramuni, 2004). The original strain was donated by the Instituto 
Nacional de Tecnologia Agropecuária (INTA, Argentina) and identified by polymerase chain reaction (PCR) (Uzal et al., 1996). All strains were kept lyophilized and stored at $-20^{\circ} \mathrm{C}$. Handling was performed according to the internal regulations of the UFMG.

\section{Toxin production}

Toxin was produced in a Bioreactor (BioFlo 110, New Brunswick Scientific Co., UK) containing five liters toxin production medium, according to Uzal et al. (1997).

\section{DNA extraction}

Clostridium perfringens was cultivated as described above in $10 \mathrm{~mL}$ toxin production medium, harvested by centrifugation at $4000 \mathrm{~g}$ for $15 \mathrm{~min}$ at $8^{\circ} \mathrm{C}$, washed in PBS and pelleted again by centrifugation. After a second round of washing, the pellet was resuspended in $200 \mu \mathrm{L}$ buffer A (50 mM Tris-HCl, pH 8, $1 \mathrm{mM}$ EDTA, pH 8, and $50 \mathrm{mM}$ D-glucose) and treated with $200 \mu \mathrm{L}$ lysis buffer (1\% SDS, $0.2 \mathrm{~N} \mathrm{NaOH}$ ) for $5 \mathrm{~min}$ at room temperature; $200 \mu \mathrm{L}$ buffer B ( $5 \mathrm{M}$ potassium acetate-acetic acid, $\mathrm{pH}$ 5.0) was then added with mixing, and the final solution was maintained on ice for $10 \mathrm{~min}$ and then centrifuged at $12,000 \mathrm{~g}$ for $8 \mathrm{~min}$ at $4^{\circ} \mathrm{C}$. The supernatant was transferred to another microcentrifuge tube, and DNA was precipitated with two volumes of ethanol. After washing with $70 \%$ ethanol, the DNA pellet was dried and dissolved in $50 \mu \mathrm{L} \mathrm{TE}$ buffer.

\section{Molecular cloning of epsilon toxin}

Based on the DNA sequence described by Hunter et al. (1992; GenBank accession number: AY858558) the primers, F 5'-GGATCCGCAATCGCATCAGCGGTGATATCC and R 5'-GGATCCCTTATTTTATTCCTGGTGCC, were designed and used to amplify the coding region of epsilon toxin. A BamHI restriction site was added to both primers (underlined in the sequences above). When the amplified fragment corresponding to nucleotides 215 to 1175 (961 bp) was expressed, it generated a truncated form of epsilon toxin lacking the first nine residues (MKKNLVKSL). PCR was carried out using Taq DNA and IVB buffer (Phoneutria Biotechnology, Belo Horizonte, $\mathrm{MG}$, Brazil). An annealing temperature of $56^{\circ} \mathrm{C}$ and 35 cycles were used. All PCR steps were $45 \mathrm{~s}$, except the last extension step, which was increased to $5 \mathrm{~min}$. A single 961-bp amplicon was obtained, purified from the agarose gel (Sambrook et al., 1989), and cloned into the pGEM-T Easy cloning vector (Promega), as recommended by the manufacturer. A transformant was obtained by transformation into $\mathrm{DH} 5 \alpha$ E. coli and selection on media containing ampicillin. This transformant was picked and used to inoculate LB medium. The plasmid was isolated from the bacterial culture with the SDS alkaline lysis method. The recombinant plasmid was sequenced with a 3130 automated DNA sequencer (ABI). DNA sequencing reactions were performed on both strands using the SP6 and T7 promoter universal primers and the $\mathrm{F}$ and $\mathrm{R}$ primers described above. The DNA sequences were analyzed using BlastX (Altschul et al., 1997). A clone with 100\% identity to the sequence described by Hunter et al. (1992) that contained the BamHI site was selected and designated pGEM- $\varepsilon$.

\section{Toxin expression}

The pGEM- $\varepsilon$ vector containing C. perfringens epsilon toxin was cleaved with BamHI. Af- 


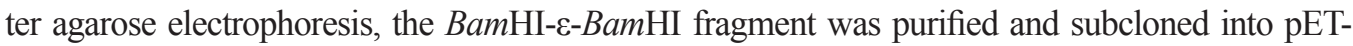
11a to generate the vector pET-11a- $\varepsilon$. DNA sequence and frame position were confirmed by DNA sequencing as described above. After transformation into BL21 E. coli, the expression of epsilon toxin was carried out as follows. BL21 cells containing the vector pET-11a- $\varepsilon$ were grown overnight at $37^{\circ} \mathrm{C}$ in $10 \mathrm{~mL} 2 \mathrm{X}$ YT medium containing ampicillin $(100 \mu \mathrm{g} / \mathrm{mL})$ and used to inoculate $100 \mathrm{~mL}$ fresh $2 \mathrm{X}$ YT medium. When the culture reached a density of $\mathrm{A}_{600}=0.5$, the recombinant vector was induced by adding IPTG $(0.6 \mathrm{mM}$ final concentration). The cells were grown for an additional $4 \mathrm{~h}$ at $37^{\circ} \mathrm{C}$, harvested by centrifugation, and washed for $15 \mathrm{~min}$ in lysis buffer $(50 \mathrm{mM}$ Tris-HCl, $\mathrm{pH} 8,1$ mM EDTA, $\mathrm{pH} 8$, and $50 \mathrm{mM}$ D-glucose) containing $4 \mathrm{mg} / \mathrm{mL}$ lysozyme. The cells were sonicated in short pulses (2-4 pulses of $15 \mathrm{~s}$ each at a power setting of 3.5; Sonifier 450) and subjected to centrifugation at $8,000 \mathrm{~g}$. The supernatant and pellet were separated on polyacrylamide gels using the Laemmli method (1970). After electrophoresis, gels were stained with Coomassie blue G-250 for identification of protein bands. The toxin protein was predominantly produced as insoluble inclusion bodies. The pellet containing the rec- $\varepsilon$ protein was further washed with lysis buffer, and after centrifugation $(12,000 \mathrm{~g})$, it was evaluated biochemically, pharmacologically, and immunologically.

\section{SDS-PAGE and Western blotting}

SDS-PAGE was carried out according to the method previously described by Laemmli (1970) using $12.5 \%$ gels. Rec- $\varepsilon$ was solubilized in reducing sample buffer. We used silver staining (Rosenberg, 1996) or Coomassie blue G-250 to detect the protein on the polyacrylamide gels. Gels were blotted onto a $0.45-\mu \mathrm{m}$ nitrocellulose membrane (Schleicher and Schuell, Keene, NH, USA), and then non-specific binding sites were blocked with PBS-T (PBS plus $0.3 \%$ Tween-20) for $1 \mathrm{~h}$ at $22^{\circ} \mathrm{C}$. The membrane was then incubated with anti-native epsilon (native- $\varepsilon$ ) toxin antibody (diluted 1:500 in PBS containing 0.05\% Tween-20) for $1 \mathrm{~h}$ at room temperature. After six washes in PBS-T (0.05\% Tween-20), the membranes were incubated for $1 \mathrm{~h}$ at room temperature in PBS-T $(0.05 \%$ Tween-20) containing anti-rabbitIgG HRP-conjugated secondary antibody. The membranes were washed three times in PBS$\mathrm{T}(0.05 \%$ Tween-20) and twice in PBS, then stained using $1 \mathrm{mg} / \mathrm{mL} 3,3$ 'diaminobenzidine (Sigma Chemical Co., St. Louis, MO, USA) in PBS with $0.04 \% \mathrm{H}_{2} \mathrm{O}_{2}$ and $8.3 \%$ methanol.

\section{Immunization}

The immunization protocol was carried out in rabbits as described by Mendes et al. (2008) using $160 \mu \mathrm{g}$ rec- $\varepsilon$ and Freund's adjuvant. Booster injections of $50 \mu \mathrm{g}$ toxin in incomplete Freund's adjuvant were given 2, 4, 10, and 20 weeks later. Immune sera were collected 10 days after the last injection and were analyzed by Western blotting and ELISA. The specific activity and titer of serum from immunized rabbits was measured by ELISA. Antibodies against the native- $\varepsilon$ toxin were also produced using the same protocol.

\section{ELISA}

Microtitration plates (Falcon 3912, Becton Dickinson, Oxnard, CA, USA) were coated overnight at $5^{\circ} \mathrm{C}$ with a $1 \mu \mathrm{g} / \mathrm{mL}$ solution of native- $\varepsilon$ toxin in $0.02 \mathrm{M}$ sodium bicarbonate buffer, pH 9.6. Anti-rec- $\varepsilon$ and native- $\varepsilon$ sera (diluted 1:100-1:1256, in PBS containing $0.25 \%$ casein and 
$0.05 \%$ Tween-20) were added, and the plate was incubated at $37^{\circ} \mathrm{C}$ for $1 \mathrm{~h}$. Peroxidase-coupled anti-rabbit antibody (Sigma) diluted 1:1000 was then added and the solution maintained for $1 \mathrm{~h}$ at $37^{\circ} \mathrm{C}$. The assay was carried out as previously described (Kalapothakis and ChávezOlórtegui, 1997). Absorbance was measured at $492 \mathrm{~nm}$ with a Titertek Multiscan plate spectrophotometer. All measurements were made in duplicate.

\section{Toxin titration}

The $\mathrm{LD}_{50}$ was determined as described by Sebald and Petit (1997) and according to the internal protocols of the Laboratory "Nacional Agropecuário/Pedro Leopoldo/Minas Gerais/ Brazil" (LANAGRO). The $\mathrm{LD}_{50}$ was then used as a parameter for the determination of $\mathrm{L}+/ 10$, which is defined as the smallest amount of toxin that will kill $50 \%$ of mice after incubation with 0.1 IU antitoxin, according to instructions from the 1998 European Pharmacopoeia. Epsilon antitoxin was obtained from the National Institute for Biological Standards and Control (NIBSC, Hertfordshire, UK). Native- $\varepsilon$ (positive control) and soluble and insoluble rec- $\varepsilon$ fractions were used with and without previous treatment with trypsin for $30 \mathrm{~min}$ at $37^{\circ} \mathrm{C}$ to check for the activation of the recombinant form by this protease. Native and recombinant toxins were sequentially diluted in PBS and mixed with antitoxin, and $0.2 \mathrm{~mL}$ was administered intravenously to Swiss mice (17-20 g body weight). Five animals were used per group.

\section{Neutralization assay}

The methodology described by Batty and Glenny (1947) was used to confirm the pharmacological characteristics of rec- $\varepsilon$. Immunological cross-reactivity was confirmed using the neutralization assay. Five doses $\left(\mathrm{LD}_{50}\right)$ of rec- $\varepsilon$ or native- $\varepsilon$ toxins were incubated for $1 \mathrm{~h}$ at $37^{\circ} \mathrm{C}$ with 0.2 $\mathrm{mL}$ immune anti-native- $\varepsilon$ or anti-rec- $\varepsilon$ antibodies, totaling four different groups. After incubation, the mixture was intravenously injected into naive Swiss mice (four animals per group). This was independently repeated three times and surviving mice were counted at $72 \mathrm{~h}$. Control trials were carried out using saline with $1 \%$ peptone instead of serum and also with pre-immune serum.

\section{Potency assay for rec- $\varepsilon$ toxin}

The assay to evaluate rec- $\varepsilon$ potency was carried out as suggested by the 1998 European Pharmacopeia, using 6-month-old rabbits (eight per group). The first group was immunized with $200 \mu \mathrm{g}$, the second with $100 \mu \mathrm{g}$ and the third with $50 \mu \mathrm{g}$ insoluble rec- $\varepsilon$ toxin. Twenty-four days after the first immunization, a booster was administered using the same amount of rec- $\varepsilon$ toxin. Bacterial extracts produced from BL21 cells transformed with the pET21-11a empty vector were used as a negative control. A pool of serum was obtained for each group and a neutralization assay was carried out as described above. Aluminum oxide $\left(\mathrm{Al}_{2} \mathrm{O}_{3}\right)$ was used as an adjuvant.

\section{Phylogenetic relationship}

We obtained the amino acid sequence of $\varepsilon$ toxin from type B C.perfringens (Accession number: Q02307.1) from the National Center Biotechnology Information (NCBI) database and made searches for similar sequences with BLASTp 2.2.21 (Altschul et al., 1997). We 
only used toxins containing the signal peptide that had high sequence similarity values. Based on the proteins found, new searches were performed, looking for the most closely related sequences. Other proteins showed high similarity, but we only used the five main toxins (alpha, beta, epsilon, iota, delta) that are produced by Clostridium.

The protein sequences found in the NCBI database were aligned using ClustalW, implemented with the MEGA 4 software (Tamura et al., 2007). The same program was used to infer the phylogenetic relationship between these sequences by neighbor-joining analyses (Saitou and Nei, 1987) based on the p-distance method. Statistical support for nodes was determined using 10,000 bootstrap replicates (Felsenstein, 1985).

\section{RESULTS}

Morphological and biochemistry analyses confirmed the characteristics of $C$. perfringens type D strain U10 (data not shown). In addition, the presence of genes encoding alpha and $\varepsilon$ toxins was confirmed by a specific PCR (Figure 1A). The PCR-amplified $\varepsilon$ toxin amplicon (Figure 1B) was purified and cloned into the expression vector pTE-11a. The construct was confirmed by DNA sequencing. The DNA sequence of $\varepsilon$ toxin was $100 \%$ identical to the sequence described by Hunter et al. (1992). The $\varepsilon$ toxin was heterologously expressed in E. coli, resulting in an efficient yield (10-15 $\mathrm{mg} / \mathrm{L}$ ) after induction with IPTG (Figure 1C). Rec- $\varepsilon$ of approximately $32 \mathrm{kDa}$ was strongly recognized by anti-native- $\varepsilon$ toxin antibodies in a Western blot assay (Figure 1D). Rec- $\varepsilon$ was expressed in an insoluble form as inclusion bodies; however, the presence of small amounts of soluble rec- $\varepsilon$ was also confirmed by Western blotting (Figure $2 \mathrm{~A}$ and $\mathrm{B}$ ). A second, strong band of $36 \mathrm{kDa}$ was frequently found after expression and purification of rec- $\varepsilon$. This band was also reactive with anti-native- $\varepsilon$ toxin antibodies (Figure 2). We used the native- $\varepsilon$ toxin as a positive control; Figure 2C shows the biochemical characterization of the purified Clostridium toxin.

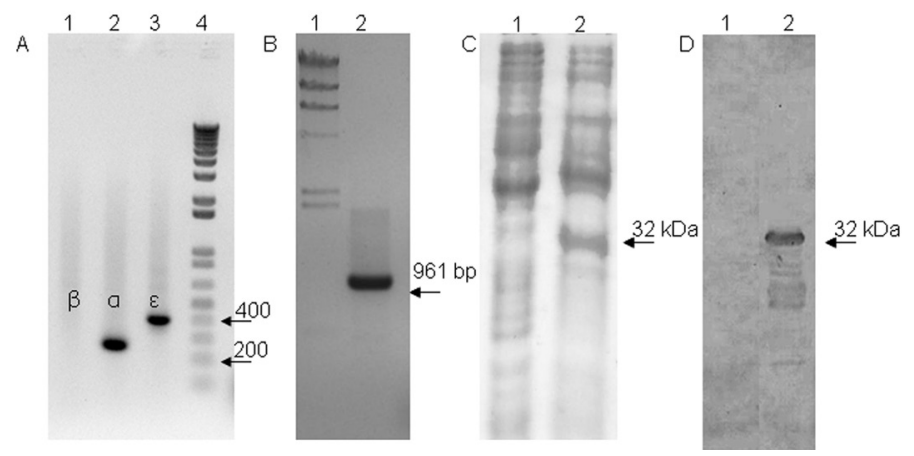

Figure 1. Epsilon ( $($ ) toxin from Clostridium perfringens type D strain U10. A. Lane $1=$ The presence of beta toxin (1025 bp, not detected); lane $2=$ alpha toxin (247 bp); lane $3=\varepsilon$ toxin (403 bp) was checked with a specific PCR; lane 4 = DNA molecular marker. B. Lane 1 = DNA molecular marker; lane $2=$ the 961-bp amplicon corresponding to nucleotides 215 to 1175 of $\varepsilon$ toxin (GenBank accession number: AY858558), used in the construction of the expression vector $\mathrm{pET}-11 \mathrm{a}-\varepsilon$. C. SDS-PAGE showing: lane $1=\mathrm{BL} 21$ Escherichia coli transformed with pET-11a empty vector used as a negative control, lane $2=\mathrm{BL} 21 \mathrm{E}$. coli transformed with pET-11a- $\varepsilon$. Induction was carried out in both cases with IPTG for $4 \mathrm{~h}$. D. Western blotting corresponding to the proteins shown in Figure 1C. Antinative- $\varepsilon$ toxin antibodies detected the recombinant $\varepsilon$ toxin (rec- $\varepsilon$ ). The presence of the $32-\mathrm{kDa}$ rec- $\varepsilon$ is shown by arrows. 

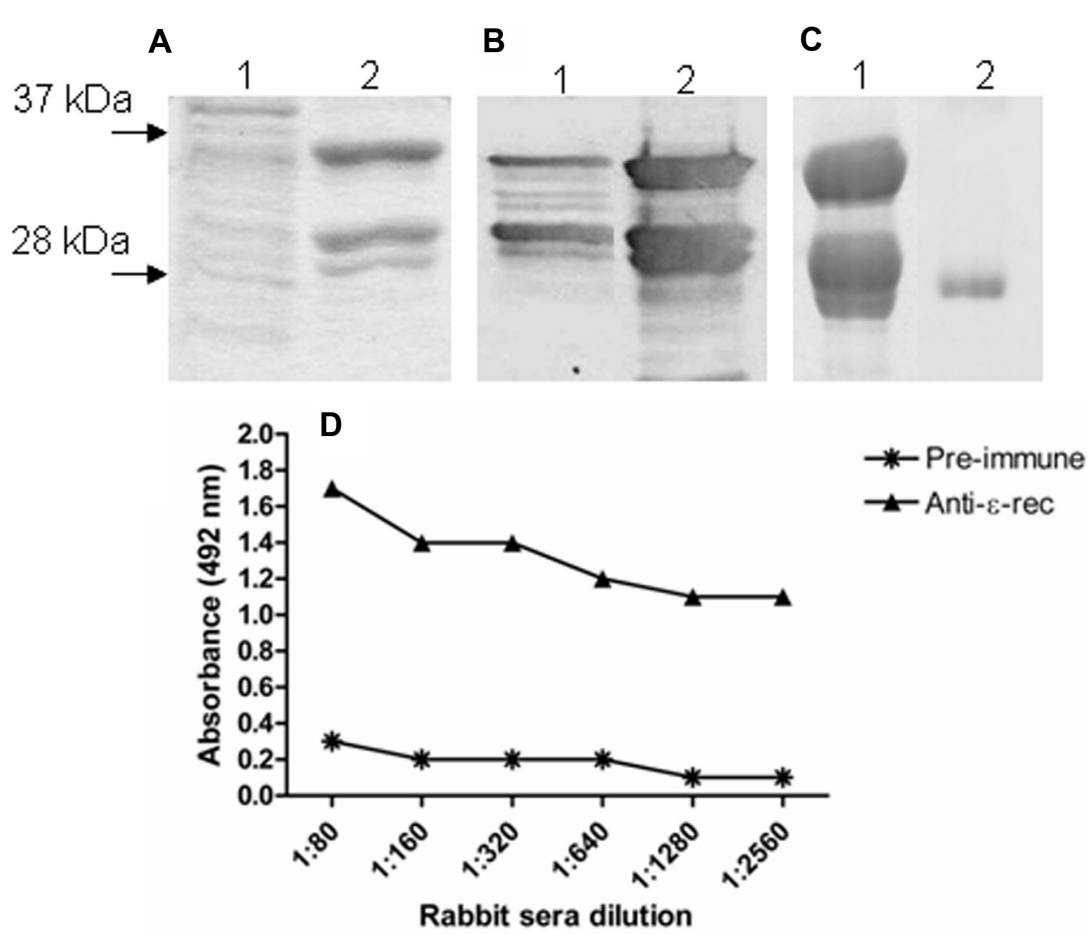

Figure 2. Purification of recombinant epsilon toxin ( $\mathrm{rec}-\varepsilon$ ) and its use in the production of antibodies. A. Lane $1=$ Soluble fraction obtained after expression of rec- $\varepsilon$ using BL21 cells transformed with pET-11a- $\varepsilon$. Lane $2=$ Inclusion bodies of rec- $\varepsilon$. B. Lanes 1 and $2=$ Western blot corresponding to the proteins shown in Figure 2A detected using anti-native- $\varepsilon$ toxin antibodies. C. Lane $1=$ Purified rec- $\varepsilon$ used for anti-rec- $\varepsilon$ antibody production. Lane $2=$ Native- $\varepsilon$ purified from Clostridium perfringens type D strain U10. D. Titration of sera from rabbits immunized with rec- $\varepsilon$. ELISA plates were pre-coated with native- $\varepsilon$ toxin $(5 \mu \mathrm{g} / \mathrm{mL})$. Pre-immune serum and anti-rec- $\varepsilon$ antibodies were diluted 1:100-1:1256. The values given are the means of duplicate assays.

Immunological, biochemical and pharmacological characterization of rec- $\varepsilon$ was carried out using the recombinant protein in the insoluble form. Anti-rec- $\varepsilon$ antibodies were prepared in rabbits; ELISA titration assays (Figure 2D) showed the cross-reactivity of this anti-recombinant toxin antibody with the native- $\varepsilon$ toxin purified from C. perfringens type $\mathrm{D}$ strain $\mathrm{U} 10$. The $\mathrm{LD}_{50}$ assays carried out with rec- $\varepsilon$ demonstrated some pharmacological toxicity in mice, despite its insoluble form. The $\mathrm{LD}_{50}$ value was $4 \mu \mathrm{g} / \mathrm{mouse}$, and no significant difference was observed after treatment with trypsin. Immunological cross-reactivity between rec- $\varepsilon$ and the native- $\varepsilon$ toxin with the corresponding anti-serum was also used for characterization of rec- $\varepsilon$ (Table 1). In this assay, carried out using mice, effective neutralization was achieved for rec- $\varepsilon$ and native- $\varepsilon$ toxin pre-incubated with antirec- $\varepsilon$ and anti-native- $\varepsilon$ antibodies. The potency assay for rec- $\varepsilon$ was carried out by immunization of rabbits with two doses of $200 \mu \mathrm{g}$ (group I), $100 \mu \mathrm{g}$ (group II) or $50 \mu \mathrm{g}$ (group III) recombinant toxin. Using pools of anti-serum ( 8 rabbits per group), values of 40, 30, and $10 \mathrm{IU} / \mathrm{mL}$ were obtained for groups I, II, and III, respectively. 
Table 1. Neutralizing capacity of anti-rec- $\varepsilon$ and anti-native- $\varepsilon$ toxin antibodies.

\begin{tabular}{llr}
\hline Experiment & \multicolumn{1}{c}{ Symptoms* } & Percent of surviving mice \\
\hline rec- $\varepsilon$ alone & Observed & $0 \%$ \\
rec- $\varepsilon+$ anti-rec- $\varepsilon$ & No symptoms observed & $100 \%$ \\
rec- $\varepsilon+$ anti-native- $\varepsilon$ & No symptoms observed & $100 \%$ \\
rec- $\varepsilon+$ pre-immune serum & Observed & $0 \%$ \\
native- $\varepsilon+$ anti-rec- $\varepsilon$ & No symptoms observed & $100 \%$ \\
native- $\varepsilon+$ anti-native- $\varepsilon$ & No symptoms observed & $100 \%$ \\
native- $\varepsilon+$ pre-immune serum & Observed & $0 \%$ \\
\hline
\end{tabular}

Five $\mathrm{LD}_{50}$ of each toxin were incubated for $1 \mathrm{~h}$ at $37^{\circ} \mathrm{C}$ with $0.2 \mathrm{~mL}$ anti-toxin. ${ }^{*}$ Lack of motor coordination, lateral decubitus, walking in circles, followed by death. rec- $\varepsilon=$ recombinant epsilon toxin; native- $\varepsilon=$ native epsilon toxin.

The phylogenetic relationships between the protein sequences of the five toxins produced by Clostridium species (alpha, beta, epsilon, iota, delta) was demonstrated in a dendrogram based on the neighbor-joining algorithm (Figure 3).

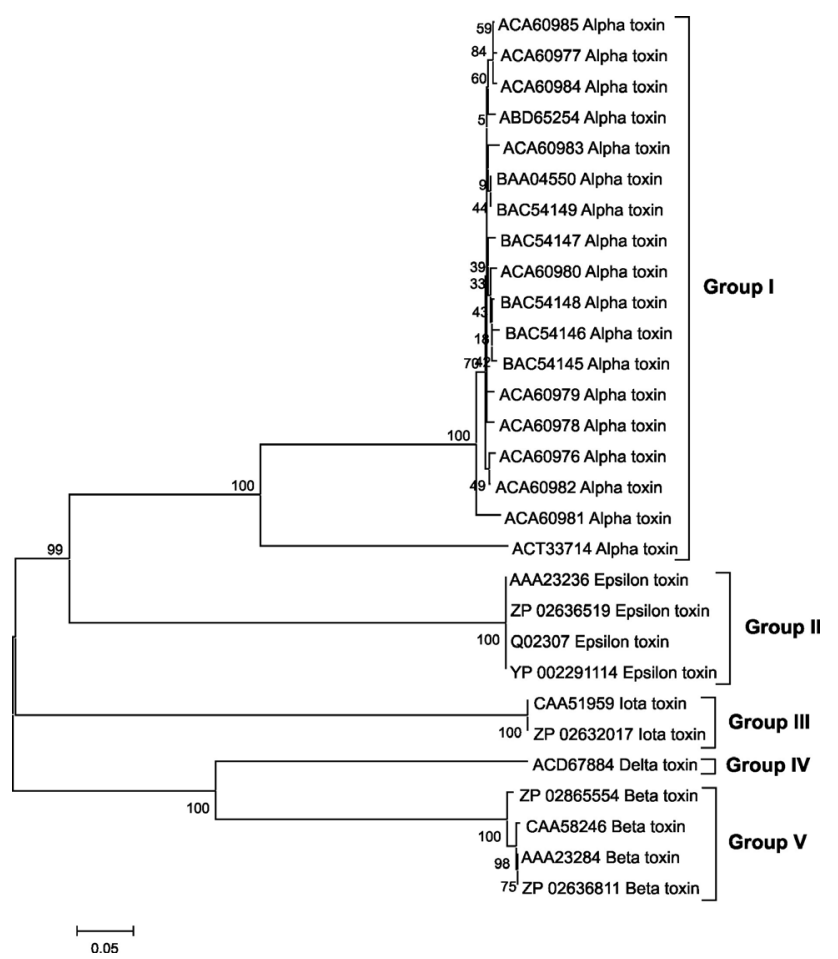

Figure 3. Dendrogram based on a neighbor-joining algorithm showing the phylogenetic relationship between the protein sequences of five toxins (alpha, beta, epsilon, iota, delta) produced by a species of Clostridium. The tree was constructed using the p-distance method; bootstrap values are shown next to branches. The size of the branches is proportional to the evolutionary distances used to infer the phylogenetic tree. The accession numbers of Clostridium toxins obtained from the NCBI database are shown close to the corresponding toxins. Alpha toxins were obtained from Clostridium septicum, except the toxin ACT33714, which came from C. botulinum. The other toxins used were from $C$. perfringens. 


\section{DISCUSSION}

Epsilon toxin is capable of crossing the blood brain barrier and reaching the brain parenchyma (Soler-Jover et al., 2007). The toxin's potential targets include vascular endothelia, synaptosomal membrane fractions, astrocytes, microglial cells, and myelin (Soler-Jover et al., 2004, 2007; Dorca-Arévalo et al., 2008). The major manifestations of epsilon neurotoxicity are microvascular endothelial injury and vasogenic edema (Ghabriel et al., 2000; Finnie et al., 1999, 2008). When high levels of $\varepsilon$ toxin are absorbed from the intestine, the resulting edema is severe and diffuse, causing neurological disorders that rapidly lead to death. If lower levels of toxin are absorbed, focal lesions are observed in the brain, termed focal symmetrical encephalomalacia (Finnie, 2004; Smedley et al., 2004; Dorca-Arévalo et al., 2008).

Many experimental models of epsilon intoxication have revealed an accumulation of the toxin in animal kidneys. Morphological alterations in the kidneys include medulla hemorrhagin and alterations of renal distal tubule cells, such as pyknotic nuclei and desquamated epithelia (Nagahama and Sakurai, 1991; Soler-Jover et al., 2004). The epithelial Madin Darby canine kidney (MDCK) cell line originating from the distal convoluted tubule is the cell line that is most sensitive to $\varepsilon$ toxin. Caucasian renal leiomyoblastoma (G-402) cells are also sensitive to this toxin (Payne et al., 1994; Petit et al., 1997). In MDCK cells, $\varepsilon$ toxin alters the cell cycle and induces cell volume increase, loss of cell viability, cytoskeletal changes, and plasma membrane functional alterations (Borrmann et al., 2001; Petit et al., 1997, 2003). Cytotoxicity may be attributed to the $\varepsilon$ toxin forming a membrane complex of about $155 \mathrm{kDa}$ and large membrane pores in MDCK cells, inducing efflux of intracellular $\mathrm{K}^{+}$and influx of $\mathrm{Cl}^{-}$and $\mathrm{Na}^{+}$; these effects can occur without the toxin entering the cytosol (Petit et al., 1997, 2003).

Due to the strong toxicity of $\varepsilon$ toxin, we decided to evaluate a recombinant form of the toxin $(\mathrm{rec}-\varepsilon)$ as a potential immunogenic toxoid for the production of a vaccine against $C$. perfringens type $\mathrm{D}$. Based on our analyses, important structures are conserved in rec- $\varepsilon$ relative to the native form. This recombinant toxin was strongly recognized by anti-native- $\varepsilon$ antibodies. We also produced antibodies with this recombinant toxin that recognized the native- $\varepsilon$ toxin and neutralized its action in mice. The toxicity of rec- $\varepsilon$ was considerably lower than that of the native toxin. The $\mathrm{LD}_{50}$ was $4.0 \mu \mathrm{g} /$ mouse. Payne et al. (1994) reported an $\mathrm{LD}_{50}$ of $0.078 \mu \mathrm{g} /$ mouse for a native- $\varepsilon$ toxin purified from $C$. perfringens type $\mathrm{D}$, which is 51 times lower than we obtained with the recombinant form that we produced. The low toxicity of rec- $\varepsilon$ allowed us to use this toxoid in rabbits without any pre-treatment to reduce toxicity. Rec- $\varepsilon$ has low toxicity because it is produced in an insoluble form when it is expressed in E. coli cells. This insoluble form of rec- $\varepsilon$ may also contribute to the high antibody titers obtained by vaccinating rabbits, due to its conserved epitopes and probable low and slow release in rabbit tissue.

Epsilon toxin has been characterized in a number of independent studies; it is well known that this toxin is synthesized and secreted as a "relatively" inactive protoxin that is converted to the active toxin by proteolytic cleavage of $\mathrm{N}$ - and C-terminal peptides (Bhown and Habeerb, 1977). Enzymatic activation can increase the specific toxicity of the protoxin up to 1000-fold (Worthington and Mulders, 1977). This activation usually occurs in the intestinal lumen of infected animals due to the action of trypsin and chymotrypsin (Worthington et al., 1973; Minami et al., 1997). In our experiment, the (low) residual toxicity exhibited by the insoluble $\varepsilon$-rec may have appeared because a small proportion of the recombinant toxin became soluble. We expected full activation of rec- $\varepsilon$ only after trypsin and chymotrypsin treatment since the re- 
combinant form was expressed with the $\mathrm{N}$-terminus site intact (except the first nine residues) and no modification of the C-terminus. Rec- $\varepsilon$ was used without any proteolytic activation to facilitate its activity as an immunogen. However, even after treatment with trypsin, no significant activation of rec- $\varepsilon$ was observed, probably because this protease is not effective on the insoluble form.

Rec- $\varepsilon$ toxin was administered in two doses with an interval of 21 days. Each dose consisted of 50, 100 and $200 \mu \mathrm{g}$ rec- $\varepsilon$ toxin emulsified in $\mathrm{Al}_{2} \mathrm{O}_{3}$. While the European Pharmacopeia (1998) and the Code of Federal Regulations (CFR, USA) predict minimum values of 5 and $2 \mathrm{IU} / \mathrm{mL}$, respectively, for antibody levels against Clostridium $\varepsilon$ toxin, we found a minimum value of $10 \mathrm{IU} / \mathrm{mL}$, obtained with $50 \mu \mathrm{g} \varepsilon$-rec in the immunization process. This is five times higher than the commonly accepted CFR minimum standard and that suggested by the Brazilian Ministry of Agriculture and Food Supply (both $2 \mathrm{IU} / \mathrm{mL}$ ). Improved results were obtained when larger amounts of rec- $\varepsilon, 100$ and $200 \mu \mathrm{g}$ (30 and $40 \mathrm{IU} / \mathrm{mL}$, respectively), were used; an even better result $(80 \mathrm{IU} / \mathrm{mL})$ was achieved with $160 \mu \mathrm{g}$ rec- $\varepsilon$ mixed with Freund's adjuvant and four boosters. This demonstrates that improved antibody levels can be obtained by altering the immunization process.

In light of our findings, we suggest that vaccine development can be improved by obtaining information on the phylogenetic relationships among Clostridium toxins. When we examined the relationships among several described toxins of $C$. perfringens, we found that they formed five distinct groups (Figure 3). Each clade was composed exclusively of one type of toxin; this result was supported by high bootstrap values. Within group I, only one alpha toxin was divergent (Accession number: ACT33714), possibly because it originates from Clostridium botulinum rather than Clostridium septicum, which was the origin of the other alpha toxins that we analyzed. We are currently working on the expression of at least one Clostridium toxin from each group shown in Figure 3, with the aim of producing a potent neutralizing serum after immunization with this pool of toxins.

\section{ACKNOWLEDGMENTS}

Research supported by FAPEMIG, PRONEX, CNPq, FEPMVZ, and CAPES. E. Kalapothakis is a recipient of a CNPq fellowship.

\section{REFERENCES}

Altschul SF, Madden TL, Schäffer AA, Zhang J, et al. (1997). Gapped BLAST and PSI-BLAST: a new generation of protein database search programs. Nucleic Acids Res. 25: 3389-3402.

Aramuni LG (2004). Seleção de Colônias de Clostridium perfringens Tipo D Produtoras de Toxina Épsilon por "Dot Blot". Master's thesis, Escola de Veterinária, UFMG, Belo Horizonte.

Batty I and Glenny AT (1947). Titration ofClostridium welchii epsilon-toxin and antitoxin. Br. J. Exp. Pathol. 28: 110-126.

Bhown AS and Habeerb AF (1977). Structural studies on epsilon-prototoxin of Clostridium perfringens type D. Localization of the site of tryptic scission necessary for activation to epsilon-toxin. Biochem. Biophys. Res. Commun. 78: 889-896.

Borrmann E, Günther H and Köhler H (2001). Effect of Clostridium perfringens epsilon toxin on MDCK cells. FEMS Immunol. Med. Microbiol. 31: 85-92.

Dorca-Arévalo J, Soler-Jover A, Gibert M, Popoff MR, et al. (2008). Binding of epsilon-toxin from Clostridium perfringens in the nervous system. Vet. Microbiol. 131: 14-25.

Felsenstein J (1985). Confidence limits on phylogenies: an approach using the bootstrap. Evolution 39: 783-791.

Finnie JW (2004). Neurological disorders produced by Clostridium perfringens type D epsilon toxin. Anaerobe 10: 145-150.

Finnie JW, Blumbergs PC and Manavis J (1999). Neuronal damage produced in rat brains by Clostridium perfringens type D epsilon toxin. J. Comp. Pathol. 120: 415-420. 
Finnie JW, Manavis J and Blumbergs PC (2008). Aquaporin-4 in acute cerebral edema produced by Clostridium perfringens type D epsilon toxin. Vet. Pathol. 45: 307-309.

Ghabriel MN, Zhu C, Reilly PL, Blumbergs PC, et al. (2000). Toxin-induced vasogenic cerebral oedema in a rat model. Acta Neurochir. (Suppl 76): 231-236.

Hunter SE, Clarke IN, Kelly DC and Titball RW (1992). Cloning and nucleotide sequencing of the Clostridium perfringens epsilon-toxin gene and its expression in Escherichia coli. Infect. Immun. 60: 102-110.

Kalapothakis E and Chávez-Olórtegui C (1997). Venom variability among several Tityus serrulatus specimens. Toxicon 35: $1523-1529$.

Laemmli UK (1970). Cleavage of structural proteins during the assembly of the head of bacteriophage T4. Nature 227: 680-685.

McClane BA (2005). Clostridial Enterotoxins. In: Handbook on Clostridia (Durre P, ed.). CRC Press, Boca Raton, 385-406.

McDonel JL (1986). Toxins of Clostridium perfringens Types A, B, C, D and E. In: Pharmacology of Bacterial Toxins (Dorner F and Drews J, eds.). Pergamon Press, Oxford, 477-517.

Mendes TM, Dias F, Horta CC, Pena IF, et al. (2008). Effective Tityus serrulatus anti-venom produced using the Ts1 component. Toxicon 52: 787-793.

Minami J, Katayama S, Matsushita O, Matsushita C, et al. (1997). Lambda-toxin of Clostridium perfringens activates the precursor of epsilon-toxin by releasing its N- and C-terminal peptides. Microbiol. Immunol. 41: 527-535.

Miyamoto K, Li J, Sayeed S, Akimoto S, et al. (2008). Sequencing and diversity analyses reveal extensive similarities between some epsilon-toxin-encoding plasmids and the pCPF5603 Clostridium perfringens enterotoxin plasmid. $J$. Bacteriol. 190: 7178-7188.

Nagahama M and Sakurai J (1991). Distribution of labeled Clostridium perfringens epsilon toxin in mice. Toxicon 29: 211-217. Niilo L (1980). Clostridium perfringens in animal disease: a review of current knowledge. Can. Vet. J. 21: 141-148.

Payne DW, Williamson ED, Havard H, Modi N, et al. (1994). Evaluation of a new cytotoxicity assay for Clostridium perfringens type D epsilon toxin. FEMS Microbiol. Lett. 116: 161-167.

Petit L, Gibert M, Gillet D, Laurent-Winter C, et al. (1997). Clostridium perfringens epsilon-toxin acts on MDCK cells by forming a large membrane complex. J. Bacteriol. 179: 6480-6487.

Petit L, Gibert M and Popoff MR (1999). Clostridium perfringens: toxinotype and genotype. Trends Microbiol. 7: 104-110.

Petit L, Gibert M, Gourch A, Bens M, et al. (2003). Clostridium perfringens epsilon toxin rapidly decreases membrane barrier permeability of polarized MDCK cells. Cell Microbiol. 5: 155-164.

Rood JI (1998). Virulence genes of Clostridium perfringens. Annu. Rev. Microbiol. 52: 333-360.

Rosenberg IM (1996). Electrophoretic Techniques. In: Protein Analysis and Purification: Benchtop Techniques. Birkhäuser, Boston, 55-98.

Saitou N and Nei M (1987). The neighbor-joining method: a new method for reconstructing phylogenetic trees. Mol. Biol. Evol. 4: 406-425.

Sambrook J, Fritsh EF and Maniatis T (1989). Molecular Cloning: a Laboratory Manual. Cold Spring Harbor Laboratory, Cold Spring Harbor.

Sebald M and Petit JC (1997). Laboratory Methods Anaerobic Bacteria and their Identification. Institut Pasteur, Paris.

Smedley JG III, Fisher DJ, Sayeed S, Chakrabarti G, et al. (2004). The enteric toxins of Clostridium perfringens. Rev. Physiol. Biochem. Pharmacol. 152: 183-204.

Soler-Jover A, Blasi J, Gomez de Aranda I, Navarro P, et al. (2004). Effect of epsilon toxin-GFP on MDCK cells and renal tubules in vivo. J. Histochem. Cytochem. 52: 931-942.

Soler-Jover A, Dorca J, Popoff MR, Gibert M, et al. (2007). Distribution of Clostridium perfringens epsilon toxin in the brains of acutely intoxicated mice and its effect upon glial cells. Toxicon 50: 530-540.

Sterne M (1981). Clostridial infections. Br. Vet. J. 137: 443-454.

Tamura K, Dudley J, Nei M and Kumar S (2007). MEGA4: Molecular Evolutionary Genetics Analysis (MEGA) software version 4.0. Mol. Biol. Evol. 24: 1596-1599.

Titball RW, Naylor CE and Basak AK (1999). The Clostridium perfringens alpha-toxin. Anaerobe 5: 51-64.

Uzal FA, Plumb JJ, Blackall LL, O’Boyle D, et al. (1996). Detection by polymerase chain reaction of Clostridium perfringens producing epsilon toxin in faeces and in gastrointestinal contents of goats. Lett. Appl. Microbiol. 23: 13-17.

Uzal FA, Plumb JJ, Blackall LL and Kelly WR (1997). PCR detection of Clostridium perfringens producing different toxins in faeces of goats. Lett. Appl. Microbiol. 25: 339-344.

Worthington RW and Mulders MS (1977). Physical changes in the epsilon prototoxin molecule of Clostridium perfringens during enzymatic activation. Infect. Immun. 18: 549-551.

Worthington RW, Mulders MS and Van Rensburg JJ (1973). Enzymatic activation of Clostridium perfringens epsilon prototoxin and some biological properties of activated toxin. Onderstepoort J. Vet. Res. 40: 151-154. 